Montrose.-Males : John A. Thomson, John Nicoll. Females : Alice McKenzie, Annie C. Milne, Cecilia Fullerton, Annie Chapman, Charlotte Buchan.

Perth District.-Females : Ella MacKenzie, Annie F. Dewar, Margaret C. Boyd. Riccartsbar.-Male : James Simpson.

Roxburgh District.-Females: Helen McFarlane, Mary A. Jarvie.

Stirling Distriot.-Males: Martin Scanlan, John T. Mowat. Females : Alice E. Forster, Janet W. Marshall, Margaret Wards, Annie E. Mulholland, Margaret Lippiatt.

IRELAND.

Ballinasloe.-Males: William Hickey, Marks Kilalea, Timothy Churchill. Females : Mary Gorman, Nora Cullinan, Mary A. Finnerty.

Clonmel.-Males : Patrick Harding, James Grady. Females: Mary Maher, Mary Milton.

Cork District.-Males : Denis Mahony, John Coughlan, John Keane. Females : Annie Murphy, Minnie Reardon, Ellie O'Brien, Nora Motherway, Mary A. Sullivan, Anna Gould, Julia Lordon, Kate Twomey.

Downpatrick.-Males: John Barry, John Murtagh, Patrick King, William James

McConvey, William James Tuft, William James Hanna, Joseph Hodgson.

Enniscorthy.-Male: James Nolan. Female : Annie Walsh.

Londonderry.-Females : Margaret Jacob, Kathleen Murphy.

Monaghan.-Males : William Haine, Arthur Graham, Peter Murphy, Joseph

Johnston, Owen Connolly, Joseph Morrow, John Stewart, Patrick McKenna

Females : Eliza Jane Clarke, Mary Ann McAdam, Mary Anne Boyle, Bridget Holland.

Portrane.-Females : Mary Kieran, Mary McGuirk, Anne Maria Orr, Kate Henneberry, Sarah Jane Taylor, Mary F. Nolan, Mary Phelan.

Richmond.-Males: John Pallis, John Brennan, Lawrence Murray, Michael

Boland, John Quinn, William McDonald. Females : Edith Casey, Mary Aungier,

Helena K. O'Beirne, Mary A. Breen, Margaret Alice Hartford, Maria McGuiness,

Elizabeth O'Callaghan.

Waterford.-Males : James McDonald, Thomas J. Dunn. Females : Catherine

Maher, Mary B. O'Toole.

St. Patrick's Hospital.-Female: Katherine S. D. Graham.

The following is a list of the questions which appeared on the paper:

1. What is meant by reflex action? Give three examples.

2. What points should a nurse attend to in the general management of a patient suffering from heart disease?

3. Describe the mental features seen in "epileptic insanity."

4. What are the special risks in cases of senile insanity, and how should they be guarded against $P$

5. A patient spits bright red blood. Where is it likely to come from, and how would you treat the patient till the doctor comes?

6. Describe the performance of artificial respiration.

7. What is a convulsion? In what diseases are convulsions most likely to occur?

8. What are the precautions to be observed in nursing patients suffering from consumption ?

9. What are the principal conditions that lead to a progressive loss of weight ?

10. What would lead you to believe that a patient suffers from hallucinations of hearing? Illustrate your answer by the signs observed in two patients known to you. Why are hallucinations of grave importance in many cases?

\title{
NURSING CERTIFICATE
}

The next examination for the Nursing Certificate will take place on Monday, the 2nd November, 1908. 